\title{
Advantages and Disadvantages of Partial High Pressure Homogenisation of Milk in Relation to Full-Stream Homogenisation
}

\author{
Katarzyna Ambroziak ${ }^{1}$, Katarzyna Kietczewska ${ }^{1 *}$, Dorota Mickiewicz ${ }^{2}$, Aneta Dabrowska ${ }^{1}$ \\ ${ }^{1}$ Department of Dairy Science and Quality Management, Faculty of Food Sciences, \\ University of Warmia and Mazury in Olsztyn, Oczapowski Str. 7, 10-719 Olsztyn, Poland \\ ${ }^{2}$ Department of Process Engineering and Equipment, Faculty of Food Sciences, \\ University of Warmia and Mazury in Olsztyn, Oczapowski Str. 7, 10-719 Olsztyn, Poland
}

Key words: viscosity, milk, acidity, colloidal stability, high pressure homogenisation, fat globule size

This study determines the effect of full-stream and partial high pressure homogenisation (constant pressure of $100 \mathrm{MPa}$, different temperatures: $20^{\circ} \mathrm{C}, 40^{\circ} \mathrm{C}, 60^{\circ} \mathrm{C}$ ) on selected distinguishing features of the colloidal and emulsion phases of milk. The $\mathrm{pH}$ values of milk decreased significantly $(p<0.05)$ as a result of full-stream homogenisation, while they remained unaffected by partial homogenisation $(p \geq 0.05)$. Most of the changes in the titratable acidity and conductivity of milk triggered by full-stream homogenisation and partial homogenisation were not statistically significant $(\mathrm{p} \geq 0.05)$. Partial high pressure homogenisation had a weaker effect on reducing rennet coagulation time and heat stability of milk than the process performed with the full-stream method. Full-stream and partial homogenisation resulted in a statistically significant $(\mathrm{p}<0.05)$ reduction in the thermal coagulation time by approx. $44 \%$ and $30 \%$, respectively in comparison to the control sample. The values of thermal stability time of milk subjected to full-stream and partial high pressure homogenisation were different $(\mathrm{p}<0.05)$. The rennet coagulation time of milk did not differ depending on the homogenisation method applied $(\mathrm{p} \geq 0.05)$. Fat globules size, described by parameters $\mathrm{d}_{\mathrm{v}} 10, \mathrm{~d}_{\mathrm{v}} 50, \mathrm{~d}_{\mathrm{v}} 90, \mathrm{~d}_{32}$, and $\mathrm{d}_{43}$, was statistically significant $(\mathrm{p}<0.05)$ lower upon fullstream homogenisation than upon partial homogenisation. The maximum decrease in $\mathrm{d}_{32}$ value was 6.5 - and 2-fold as a result of full-stream and partial homogenisation, respectively. Microscopic images show that the low effectiveness of partial homogenisation was due to the flocculation of fat globules. Changes to the viscosity of milk as a result of full-stream homogenisation (a decrease) and partial homogenisation (an increase) were noted as well.

The advantage of partial high pressure homogenization over full-stream homogenization is the reduction of the influence of the process on the colloidal stability of milk, while the disadvantage is the low efficiency of the process. High pressure homogenization as an innovative method of preservation can be applied in the dairy industry. The desired features of emulsion and colloidal phases, depending on the product, are the result of selection of the method and temperature of the process.

\section{INTRODUCTION}

Milk and dairy products are dietary components with a comprehensive nutritional value, due to the large variety of valuable ingredients, their high bioavailability and biological activity. These include: proteins, bioactive peptides derived from proteins (fermented beverages) or only from casein (cheese), enzymes, vitamins, minerals, particularly calcium, and components of the emulsion phase, i.a. conjugated linoleic acid, short-chain and medium-chain fatty acids, polar lipids, and fat-soluble vitamins [Korhonen, 2009; Park, 2009].

The heat treatment is a commonly used method in the dairy industry. In an attempt to reduce undesirable changes in milk components, the alternative methods have become popular in the design of functional foods. Alternative methods of food preservation include, among others, mechanical methods based on the separation of microorganisms from milk using centrifugal force (bactofugation) or mem-

\footnotetext{
* Corresponding Author: Tel.: (48 89523 3211); Fax: (48 89523 3402);

E-mail: kaka@uwm.edu.pl (K. Kiełczewska)
}

branes (microfiltration) or the use of pulsed electric field, ultrasounds, pressurisation, and high pressure homogenisation [Butz \& Tauscher 2002; Datta \& Deeth, 2003; Devlieghere et al., 2004]. The prerequisite for using the emerging technologies in the food production is their actions, which do not impair the nutritional value or organoleptic properties of food, and improve its shelf-life by limiting the development or by eliminating microorganisms. They have a potential to provide fresh-like products with the prolonged shelf-life and desired rheological characteristics, sensory properties, and nutritional value. Moreover, emerging technologies are potential methods for the fractionation of milk compounds [Kumar et al., 2013] and for the production of novel functional dairy products as whey-based drinks [Pereira et al., 2015], whey protein-based emulsions [Yan et al., 2017], fermented dairy beverages [Masson et al., 2011], and functional food supplements containing heat-sensitive components of milk [Aguayo et al., 2017].

High pressure homogenisation $(\mathrm{HPH})$ is a process carried out under dynamic pressure ranging from 100 to $400 \mathrm{MPa}$. When the process is carried out in a narrow pres- 
sure range of 300-400 $\mathrm{MPa}$, it is usually referred to as ultra-high pressure homogenisation (UHPH) [Georget et al., 2014]. The process, also referred to as dynamic high pressure treatment, may potentially be applied in the pharmaceutical, cosmetic, and food industries, including in the dairy sector [Dumay et al., 2013]. In milk and cream of varying fat contents, the process is applied to disperse the emulsion phase in the continuous (dispersing) phase, i.e. plasma (milk components except the emulsion phase) and to obtain small-sized fat globules. An important consequence of high pressure homogenisation is its contribution to the reduction in the microbial count in milk to a degree dependent on process parameters (pressure, temperature) [Georget et al., 2014; Hayes \& Kelly, 2003a; Pedras et al., 2012; Rodarte et al., 2018]. An additional aspect of replacing pasteurisation with this process is the reduction in adverse environmental impact [Valsasina et al., 2017]. High pressure homogenisation, as an emerging technology, may be applied in the production of dairy products to replace both pasteurisation and homogenisation. The desired effect of both obtaining the dispersion of milk fat and an improvement in microbiological quality of a product occurs while applying high pressure homogenisation at a cooling or room temperature, i.e. at a temperature lower than that during homogenisation under typical conditions, i.e. below $60^{\circ} \mathrm{C}$ [Pereda et al., 2007; Thiebaud et al., 2003]. Another effect of the application of high pressure homogenisation, which is of significance given the shelf-life of dairy products, is the inactivation of native milk enzymes such as alkaline phosphatase or, partially, peroxidase, as well as plasmin [Hayes \& Kelly, 2003b; Pereda et al., 2007]. Finally, high pressure homogenisation enables the modification of the remaining non-fat components of milk and its functional characteristics applied in the dairy industry [Hernández \& Harte, 2008; Pedras et al., 2014; Roach \& Harte, 2008; Sandra \& Dalgleish, 2005, 2007; Sørensen et al., 2014].

In a process line for non-fermented milk beverages, either full-stream or partial homogenisation process may be applied. During full-stream homogenisation, milk with the previously standardized fat content is subjected to the process. In turn, during partial homogenisation, only the cream previously obtained from the centrifugation of raw milk (and not the obtained skimmed milk) is subjected to the process. The next stage is the standardisation of the fat content of the skimmed milk with homogenised cream [Innings, 2015]. The fact that the skimmed milk remains non-subjected to homogenisation is of particular importance due to the effect of homogenisation on plasma components and on the properties of milk [Kiełczewska et al., 2008; Pereda et al., 2009; Zamora et al., 2012]. The application of partial homogenisation (during which only the previously obtained cream subsequently combined at a specific ratio with the skimmed milk, is subjected to the treatment) is also economically justified. In contrast to homogenisation performed in full-stream mode, it provides an opportunity to install homogenisers with significantly lower capacities than the capacity of the entire line on process lines. When designing a process line to account for partial homogenisation, preservation (thermal or mechanical through microfiltration or bactofugation) may be applied separately to skimmed or standardized milk as the last stage of the tech- nological process. At the same time, there is little research on preserving natural milk structure in the technological process, and the results of excessive interference with the milk structure may not be neutral to the human body.

The aim of this study was to compare effects of full-stream and partial high pressure homogenisation on selected properties of milk, with particular emphasis on the distinguishing features of emulsion and colloidal phases.

\section{MATERIAL AND METHODS}

\section{Research material}

The research material was cow milk originating from the Bałdy Educational and Research Station of the University of Warmia and Mazury in Olsztyn, cooled to a temperature of $\leq 4^{\circ} \mathrm{C}$, and preserved by the addition of a $2 \%$ sodium azide solution in an amount of $1 \mathrm{~mL}$ per $1 \mathrm{~L}$ in order to inhibit the growth of microorganisms. Bulk tank milk was sampled six times. The entire research was conducted in the Autumn 2017 and took 2 months.

\section{Preparation of samples for homogenisation}

Raw milk was centrifuged at a temperature of $45^{\circ} \mathrm{C}$ using a skimming centrifuge (Gea Westfalia Separator System GmbH, Oelde, Germany) to obtain skimmed milk and cream. Raw milk was standardized with skimmed milk to a fat content of $3.5 \%$ and earmarked for full-stream homogenisation. The cream was standardized to a fat content of $20 \%$ and earmarked for partial homogenisation and the subsequent standardisation of the skimmed milk to a fat content of $3.5 \%$.

\section{Homogenisation process}

High pressure homogenisation of $800 \mathrm{~mL}$ of milk and $800 \mathrm{~mL}$ of cream was carried out at a constant pressure of $100 \mathrm{MPa}$ and at various initial temperatures of $20^{\circ} \mathrm{C}, 40^{\circ} \mathrm{C}$, and $60^{\circ} \mathrm{C}$. Homogenisation was carried out using a Panda-PLUS 2000 homogeniser (Gea Niro Soavi, Parma, Italy).

The control sample was unhomogenised milk standardised to $3.5 \%$.of fat content.

\section{Acidity and conductivity measurements}

The acidity of milk was assessed based on the measurements of its $\mathrm{pH}$ using an inoLab Level $1 \mathrm{pH}$ meter (WTW, Weilheim, Germany) and its titratable acidity. Milk (100 mL) was titrated with $0.25 \mathrm{M} \mathrm{NaOH}$ using phenolphthalein as the indicator [AOAC, 1990; method 947.05]. The results were expressed as Soxhlet-Henkel degrees ( $\left.{ }^{\circ} \mathrm{SH}\right)$. The conductivity of milk was measured using an inoLab Cond Level 1 conductometer (WTW, Weilheim, Germany).

\section{Colloidal stability of milk}

An assessment was performed of heat stability of milk expressed as the thermal coagulation time at a temperature of $140^{\circ} \mathrm{C}$ in an oil bath (TewesBis, Barczewo, Poland) [Kruk et al., 1979], and the rennet coagulation time [Petrovska et al., 2017], using Chy-Max preparation (Chr. Hansen, Hørsholm, Denmark). 


\section{Fat globule size}

An analysis of fat globule size measured with laser diffraction was carried out using a Mastersizer 3000 particle size analyser equipped with He-Ne laser $(632.8 \mathrm{~nm})$ with a Hydro EV dispersion unit (Malvern Instrument, Malvern, United Kingdom). The measurement was carried out using deionized water (Milli-Q, Millipore, Molsheim, France) and milk with refractive indexes 1.33 and 1.46 , respectively.

The following parameters were determined:

- $\mathrm{d}_{\mathrm{v}} 10$ - the diameter below which lies $10 \%$ of globules volume,

- $\mathrm{d}_{\mathrm{v}} 50$ - median diameter, $50 \%$ of the volume distribution is above, and $50 \%$ is below observed diameter,

- d 90 - the diameter below which lies $90 \%$ of globules volume,

- span as $\left(\mathrm{d}_{\mathrm{v}} 90-\mathrm{d}_{\mathrm{v}} 10\right) / \mathrm{d}_{\mathrm{v}} 50$,

- a volume-surface mean diameter of fat globules (Sauter Mean Diameter) $\mathrm{d}_{32}=\Sigma \mathrm{d}_{\mathrm{i}}^{3} \mathrm{n}_{\mathrm{i}} / \Sigma \mathrm{d}_{\mathrm{i}}^{2} \mathrm{n}_{\mathrm{i}}$,

- a mean diameter over volume (De Brouckere Mean Diameter) $\mathrm{d}_{43}=\Sigma \mathrm{d}_{\mathrm{i}}^{4} \mathrm{n}_{\mathrm{i}} / \Sigma \mathrm{d}_{\mathrm{i}}^{3} \mathrm{n}_{\mathrm{i}}$

- the specific surface area of fat globules in $1 \mathrm{~g}$ of milk fat, $s s a=6 / d_{32}$,

where $n_{i}$ is the number of fat globules with a diameter of $d_{i}$.

\section{Microscopic analysis}

The state of dispersion of milk fat in the milk and cream was assessed by the microscopic method using a Nikon Eclipse Ti-E confocal microscope (Nikon Instruments, Amsterdam, The Netherlands). Microscopic specimens of milk and cream samples were prepared according to the requirements of PNA-86059:1975, using a solution of 2-naphthalenol,1-[2-[4-(2-phenyldiazenyl)phenyl]diazenyl] (Merck, Darmstadt, Germany) in ethanol. The observation and recording of microscopic images were performed at a magnification of 60 .

\section{Shear flow and viscosity}

Shear stress and viscosity of milk were determined at a temperature of $20^{\circ} \mathrm{C}$ with a rotational rheometer (RheolabQC, Anton Paar GmbH, Graz, Austria) using a system of DG42/ SS concentric cylinders. The samples were subjected to shear stress at a rate increasing within the range of $0-100 / \mathrm{s}$. Given the considerable fluctuations of the analysed rheological val- ues at a shear rate of $<16$, the manuscript provides measurement results at a shear rate within the range of 16-100/s.

\section{Statistical analysis}

Six independent experiments were conducted $(n=6)$. Each laboratory analysis was performed in two replications. Test results were presented as mean values and their variation was expressed using standard deviations. The obtained data were compared using ANOVA and the least significant difference (LSD) test. A statistical analysis was carried out using software of StatSoft Inc. Statistica v. 10.0 (Tulsa, OK, USA).

\section{RESULTS AND DISCUSSION}

The $\mathrm{pH}$ values of milk decreased significantly $(\mathrm{p}<0.05)$ as a result of full-stream homogenisation (Table 1). The $\mathrm{pH}$ values of control sample and partially homogenised milk did not differ statistically $(\mathrm{p} \geq 0.05)$. An increase $\left(\mathrm{T}=20\right.$ and $\left.60^{\circ} \mathrm{C}\right)$ in the titratable acidity of milk as a result of full-stream homogenisation and a decrease (all temperatures) as a result of partial homogenisation were not statistically significant $(p \geq 0.05)$. In the case of titratable acidity, the values characterising milk subjected to full-stream and partial high pressure homogenisation differed significantly $(p<0.05)$. Conductivity fluctuations were insignificant $(\mathrm{p} \geq 0.05)$ and this milk characteristic was regarded as invariable upon performing homogenisation. In most cases, the differentiation of homogenisation temperature did not contribute to statistically significant changes $(\mathrm{p} \geq 0.05)$ in the values of the analysed distinguishing features of acidity and conductivity (Table 1).

The literature data indicate a decrease in the $\mathrm{pH}$ value of milk as an effect of high pressure homogenisation [Hayes $\&$ Kelly, 2003a] or the lack of a significant effect of the process on this characteristic of milk [Kiełczewska et al., 2003; Pedras et al., 2014]. Conductivity of homogenised milk results from transformations of two phases, i.e. the emulsion phase, whose dispersion increase can contribute to the increase in impedance, and the soluble phase, related to the increase of its mineral salt content as a result of casein modification, which contributes to an increase in admittance [Banach et al., 2008]. Changes in the electrical properties of milk as a result of the process are probably balanced out, which is reflected

TABLE 1. The effect of full-stream and partial homogenisation on selected physicochemical properties of milk.

\begin{tabular}{|c|c|c|c|c|c|c|}
\hline \multicolumn{2}{|l|}{ Product } & $\mathrm{pH}$ & $\begin{array}{c}\text { Titratable } \\
\text { acidity }\left({ }^{\circ} \mathrm{SH}\right)\end{array}$ & $\begin{array}{l}\text { Conductivity } \\
(\mathrm{mS} / \mathrm{cm})\end{array}$ & $\begin{array}{c}\text { Rennet coagulation } \\
\text { time (min) }\end{array}$ & $\begin{array}{c}\text { Thermal } \\
\text { coagulation } \\
\text { time (min) }\end{array}$ \\
\hline \multicolumn{2}{|l|}{ Unhomogenised milk } & $6.73 \pm 0.04^{\mathrm{a}}$ & $6.70 \pm 0.11^{\mathrm{bc}}$ & $4.79 \pm 0.08^{a}$ & $4.02 \pm 0.33^{\mathrm{a}}$ & $10.18 \pm 0.29^{a}$ \\
\hline \multirow{3}{*}{$\begin{array}{c}\text { full-stream } \\
\text { homogenisation }\end{array}$} & $\mathrm{T}=20^{\circ} \mathrm{C}$ & $6.68 \pm 0.03^{b}$ & $6.92 \pm 0.28^{\mathrm{ab}}$ & $4.82 \pm 0.12^{\mathrm{a}}$ & $3.27 \pm 0.34^{\mathrm{c}}$ & $5.73 \pm 0.24^{\mathrm{c}}$ \\
\hline & $\mathrm{T}=40^{\circ} \mathrm{C}$ & $6.67 \pm 0.04^{b}$ & $6.98 \pm 0.11^{\mathrm{a}}$ & $4.83 \pm 0.13^{\mathrm{a}}$ & $3.32 \pm 0.43^{c}$ & $5.88 \pm 0.27^{\mathrm{c}}$ \\
\hline & $\mathrm{T}=60^{\circ} \mathrm{C}$ & $6.68 \pm 0.04^{b}$ & $6.72 \pm 0.18^{b c}$ & $4.83 \pm 0.11^{\mathrm{a}}$ & $3.52 \pm 0.35^{b c}$ & $5.70 \pm 0.26^{c}$ \\
\hline \multirow{3}{*}{$\begin{array}{c}\text { partial } \\
\text { homogenisation }\end{array}$} & $\mathrm{T}=20^{\circ} \mathrm{C}$ & $6.71 \pm 0.03^{\mathrm{ab}}$ & $6.51 \pm 0.18^{\mathrm{c}}$ & $4.78 \pm 0.11^{\mathrm{a}}$ & $3.62 \pm 0.17^{\mathrm{bcA}}$ & $7.02 \pm 0.18^{\mathrm{b}}$ \\
\hline & $\mathrm{T}=40^{\circ} \mathrm{C}$ & $6.71 \pm 0.03^{\mathrm{ab}}$ & $6.53 \pm 0.21^{\mathrm{c}}$ & $4.77 \pm 0.16^{\mathrm{a}}$ & $3.70 \pm 0.24^{\mathrm{bc}}$ & $7.23 \pm 0.31^{b}$ \\
\hline & $\mathrm{T}=60^{\circ} \mathrm{C}$ & $6.72 \pm 0.02^{\mathrm{a}}$ & $6.51 \pm 0.37^{c}$ & $4.75 \pm 0.11^{\mathrm{a}}$ & $3.78 \pm 0.16^{\mathrm{ab}}$ & $7.05 \pm 0.26^{\mathrm{b}}$ \\
\hline
\end{tabular}

Results are expressed as mean value \pm standard deviation. The values in the column marked with different letters differ significantly at $\mathrm{p}<0.05$. 
TABLE 2. The effect of full-stream and partial homogenisation on the distinguishing features of the dispersion of the emulsion phase of milk.

\begin{tabular}{|c|c|c|c|c|c|c|c|c|c|}
\hline \multicolumn{3}{|c|}{ Product } & $\mathrm{d}_{\mathrm{v}} 10(\mu \mathrm{m})$ & $\mathrm{d}_{\mathrm{v}} 50(\mu \mathrm{m})$ & $\mathrm{d}_{\mathrm{v}} 90(\mu \mathrm{m})$ & span & $\mathrm{d}_{32}(\mu \mathrm{m})$ & $\mathrm{d}_{43}(\mu \mathrm{m})$ & $\mathrm{ssa}\left(\mathrm{m}^{2} / \mathrm{g}\right)$ \\
\hline \multicolumn{3}{|c|}{ Unhomogenised milk } & $1.27 \pm 0.14^{\mathrm{a}}$ & $3.56 \pm 0.14^{b}$ & $6.85 \pm 0.65^{\mathrm{c}}$ & $1.57 \pm 0.21^{\mathrm{e}}$ & $2.37 \pm 0.09^{\mathrm{a}}$ & $4.86 \pm 0.44^{\mathrm{c}}$ & $2.53 \pm 0.09 \mathrm{~g}$ \\
\hline \multirow{6}{*}{ 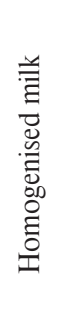 } & \multirow{3}{*}{$\begin{array}{c}\text { full-stream } \\
\text { homogenisation }\end{array}$} & $\mathrm{T}=20^{\circ} \mathrm{C}$ & $0.27 \pm 0.02^{\mathrm{c}}$ & $0.74 \pm 0.08^{e}$ & $3.53 \pm 0.41^{\mathrm{d}}$ & $4.41 \pm 0.57^{\mathrm{a}}$ & $0.59 \pm 0.03^{\mathrm{e}}$ & $2.31 \pm 0.14^{\mathrm{d}}$ & $10.24 \pm 0.51^{\mathrm{c}}$ \\
\hline & & $\mathrm{T}=40^{\circ} \mathrm{C}$ & $0.23 \pm 0.02^{\mathrm{c}}$ & $0.48 \pm 0.07^{\mathrm{f}}$ & $2.35 \pm 0.52^{\mathrm{e}}$ & $4.38 \pm 0.63^{\mathrm{a}}$ & $0.43 \pm 0.04^{\mathrm{f}}$ & $2.13 \pm 0.14^{\mathrm{d}}$ & $13.94 \pm 1.21^{\mathrm{b}}$ \\
\hline & & $\mathrm{T}=60^{\circ} \mathrm{C}$ & $0.21 \pm 0.00^{c}$ & $0.41 \pm 0.00^{\mathrm{f}}$ & $0.96 \pm 0.04^{\mathrm{f}}$ & $1.82 \pm 0.09^{\mathrm{de}}$ & $0.37 \pm 0.00^{\mathrm{g}}$ & $0.61 \pm 0.06^{\mathrm{e}}$ & $16.16 \pm 0.17^{\mathrm{a}}$ \\
\hline & \multirow{3}{*}{$\begin{array}{c}\text { partial } \\
\text { homogenisation }\end{array}$} & $\mathrm{T}=20^{\circ} \mathrm{C}$ & $0.53 \pm 0.06^{\mathrm{b}}$ & $4.91 \pm 0.12^{\mathrm{a}}$ & $11.77 \pm 1.29^{\mathrm{a}}$ & $2.29 \pm 0.21^{\mathrm{c}}$ & $1.86 \pm 0.06^{\mathrm{b}}$ & $8.62 \pm 0.80^{\mathrm{a}}$ & $3.22 \pm 0.11^{\mathrm{f}}$ \\
\hline & & $\mathrm{T}=40^{\circ} \mathrm{C}$ & $0.48 \pm 0.01^{\mathrm{b}}$ & $2.81 \pm 0.20^{c}$ & $8.92 \pm 0.53^{\mathrm{b}}$ & $3.01 \pm 0.23^{\mathrm{b}}$ & $1.36 \pm 0.04^{c}$ & $5.85 \pm 0.54^{b}$ & $4.43 \pm 0.13^{\mathrm{e}}$ \\
\hline & & $\mathrm{T}=60^{\circ} \mathrm{C}$ & $0.47 \pm 0.00^{\mathrm{b}}$ & $1.56 \pm 0.04^{\mathrm{d}}$ & $3.82 \pm 0.35^{\mathrm{d}}$ & $2.15 \pm 0.19^{\mathrm{cd}}$ & $1.06 \pm 0.02^{\mathrm{d}}$ & $4.34 \pm 0.52^{\mathrm{c}}$ & $5.66 \pm 0.08^{\mathrm{d}}$ \\
\hline
\end{tabular}

$d_{v} 10$ - size where $10 \%$ of the population is below; $d_{v} 50$ - size where $50 \%$ of the population is below/above; $d_{v} 90$ - size where $90 \%$ of the population is below; span - distribution width; $d_{32}$ - Sauter Mean Diameter; $d_{43}-$ De Brouckere Mean Diameter; ssa - the specific surface area of fat globules. Results are expressed as mean value \pm standard deviation. The values in the column marked with different small letters differ significantly at $\mathrm{p}<0.05$.

in the absence of any effect caused by the process on milk conductivity.

The application of high pressure homogenisation resulted in the lowering of the resistance of milk to the effects of coagulating factors, i.e. a high temperature or a proteolytic enzyme. This is reflected in the reduction in the thermal coagulation time and rennet coagulation time to a degree determined by the way the process was carried out, and by the temperature of milk intended for homogenisation (Table 1). The rennet coagulation time of milk was reduced as a result of full-stream homogenisation carried out at $20^{\circ} \mathrm{C}, 40^{\circ} \mathrm{C}$, and $60^{\circ} \mathrm{C}$ by $19 \%, 17 \%$, and $12 \%$, respectively, as compared to the control sample. In turn, partial homogenisation contributed, though to a lesser extent, to changes in the rennet coagulation time of milk, which, in the case of temperatures of $20^{\circ} \mathrm{C}$, $40^{\circ} \mathrm{C}$, and $60^{\circ} \mathrm{C}$ amounted to $12 \%, 10 \%$, and $9 \%$, respectively (statistically insignificant changes at $\alpha=0.05$ ). A similar trend in changes depending on the homogenisation method was also observed for heat stability. Full-stream homogenisation carried out at temperatures of $20^{\circ} \mathrm{C}, 40^{\circ} \mathrm{C}$, and $60^{\circ} \mathrm{C}$ resulted in a statistically significant $(\mathrm{p}<0.05)$ reduction in the thermal coagulation time by $44 \%, 42 \%$, and $44 \%$, respectively, while partial homogenisation carried out at analogous temperatures caused reductions by $31 \%, 29 \%$, and $31 \%$, respectively. The obtained results indicate that the way the process is carried out contributes to changes in the analysed properties of milk to a greater extent than the temperature of milk intended for homogenisation. In particular, this is reflected in statistically significant differences $(p<0.05)$ between the values of heat stability of milk subjected to full-stream and partial high pressure homogenisation.

The literature data indicate a reduction in the rennet coagulation time of milk and a change to the properties of rennet curd [Zamora et al., 2007], as well as a decrease in ethanol stability [Amador-Espejo et al., 2014] and in heat stability [Kiełczewska et al., 2008] as a result of high pressure homogenisation. The following are responsible for the decrease in the resistance of homogenised milk to coagulation factors: the loss of dynamic balance of proteins due to the dissociation of a portion of certain fractions of micellar casein, including the fraction $\kappa$ serving the protective function over casein micelles [Sandra \& Dalgleish, 2005], the denaturation of whey proteins [Pereda et al., 2009], and the adsorption of protein components of milk plasma on the interfacial surface [Zamora et al., 2012].

Modification of the colloidal phase leads to a loss of balance of mineral salts of milk due to the dissociation of the colloidal calcium phosphate and phosphorus and an increase in the soluble phase of milk [Kiełczewska et al., 2008; Zamora et al., 2007]. Such destabilisation of the colloidal phase components, i.e. proteins and mineral salts is reflected in the change in the distinguishing features of technological suitability, i.e. heat stability and rennet coagulation time as well as the acidity and the conductivity of milk [Banach et al., 2008; Kiełczewska et al., 2003]. The research presented in this publication indicates that rennet coagulation time and heat stability of milk following partial homogenisation are closer to the values found for non-homogenised milk, and are longer than the corresponding values for the discussed features in milk subjected to full-stream homogenisation. Thus, it can be concluded that milk subjected to partial homogenisation has a longer shelf-life in the aspect of colloidal phase, preserving other production parameters in relation to milk subjected to full-stream homogenisation.

The effect of high pressure homogenisation on an increase in the sensitivity of full fat milk to coagulation factors is of particular significance during the preservation of dairy products using high temperatures and determines their storage stability. Carrying out high pressure homogenisation, due to the simultaneous action of preserving factors, i.e. pressure and temperature, enables the modification of milk technology and, when the parameters are optimised, provides the possibility of affecting the physicochemical properties of milk that are significant from a practical point of view. The application of partial homogenisation, which only involves homogenisation of cream, while skimmed milk, including all its components, remains unhomogenised, contributes to a lesser extent to changes in the discussed characteristics of milk. An additional issue is the impact of high pressure homogenisation on sensory properties of milk. Previous studies [Amador-Espejo et al., 2014] did not indicate the influence of pressure homogenisation on the sensory characteristics of milk. However, research 
A
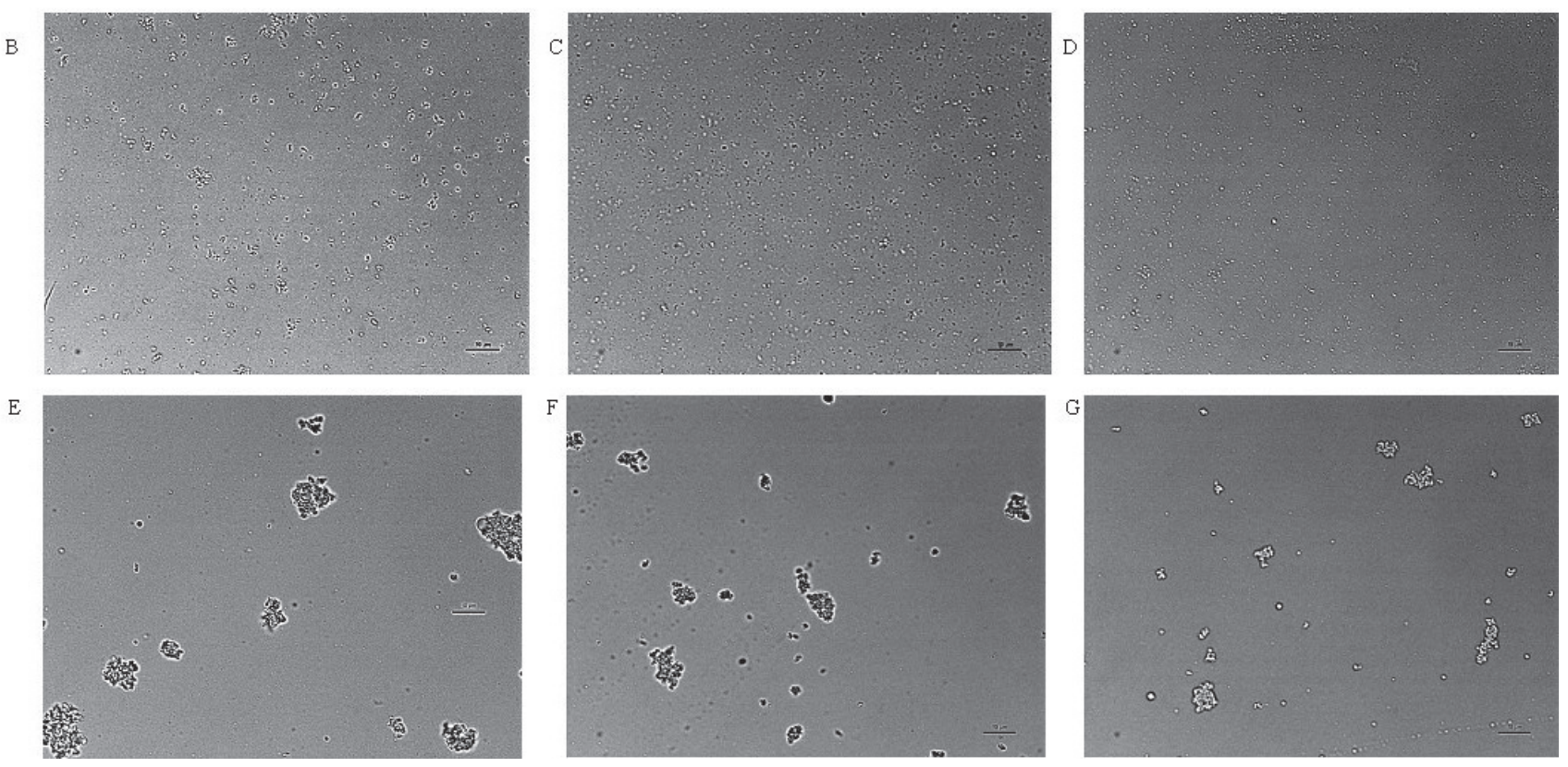

FIGURE 1. Microscopic images of unhomogenised milk (A) and milk homogenised under pressure of $100 \mathrm{MPa}$ using the full-stream homogenisation at temperatures of $20^{\circ} \mathrm{C}(\mathrm{B}), 40^{\circ} \mathrm{C}(\mathrm{C})$, and $60^{\circ} \mathrm{C}(\mathrm{D})$; and the partial homogenisation at temperatures of $20^{\circ} \mathrm{C}(\mathrm{E}), 40^{\circ} \mathrm{C}(\mathrm{F})$, and $60^{\circ} \mathrm{C}(\mathrm{G})$.

on the impact of partial-stream homogenisation, in comparison with full-stream method, using quantitative and qualitative consumer methods and sensory analysis would be useful.

The main aim of homogenisation is to reduce and unify the sizes of fat globules. The effectiveness of the high pressure homogenisation process, i.e. the degree of reduction in (and unification of) the sizes of fat globules is determined by many factors, the most important of which include the composition of the emulsion (fat and non-fat dry matter contents), homogenisation parameters (pressure and temperature), the type and design of the homogeniser valve, the number of homogenisation steps, Thoma number [Kessler, 1981], and the way the process is carried out (full-stream and partial homogenisation).

The results of the performed measurements indicated the effect of full-stream and partial homogenisation on the reduction of all distinguishing features of fat globule sizes to range depending on temperature (Table 2). Many authors indicate the effect of increasing temperature of high pressure homogenisation on the reduction of fat globule sizes in milk [Hayes \& Kelly, 2003a; Thiebaud et al., 2003; Zamora et al., 2012].

In the course of this study, higher values of the distinguishing features of dispersion of the emulsion phase were noted in the milk homogenised partially as compared to the milk homogenised by the full-stream method at analogous temperatures. Full-stream homogenisation contributed to a 4-4.4-fold decrease in the $\mathrm{d}_{32}$ value, while partial homogenisation only resulted in 1.3-2.2-fold changes in comparison to the control sample. A reduction in fat globule sizes is associated with an increase in their surface, which is appropriate to the way the process is carried out (homogenisation method, temperature). Statistically significant differences $(\mathrm{p}<0.05)$ were demonstrated in the values describing the size of fat globules and their surface area depending on both the way homogenisation was carried out and the temperature applied.

In the milk subjected to partial homogenisation, the occurrence of large-sized particles was found, characterised by high values of $d_{v} 90$ and $d_{43}$, which are greater in size than values in the non-homogenised milk. This phenomenon can be explained by supplementing instrumental studies with an analysis of microscopic images of the emulsions under study, which provide information on the dispersion of fat globules, and primarily the occurrence and identification of the forms of emulsion instability, e.g. the flocculation of fat globules. Based on the analysis of microscopic images, it was found that particular fat globules in milk homogenised by both the full-stream and partial method had smaller sizes than those characterising fat globules in the unhomogenised milk 
A

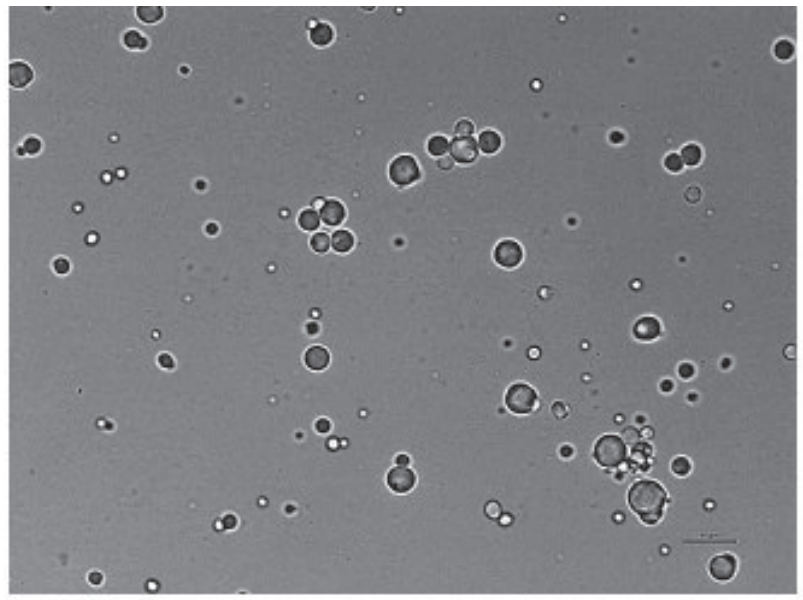

$\mathrm{C}$

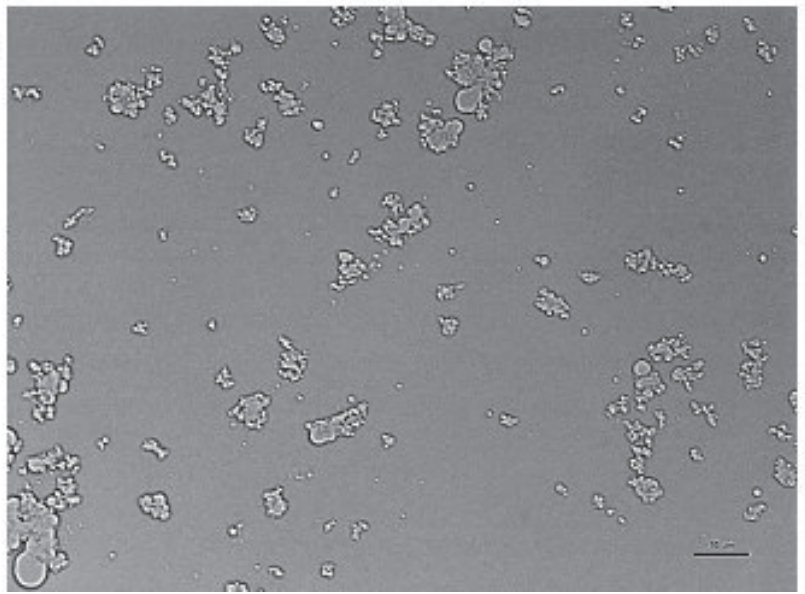

$\mathrm{B}$

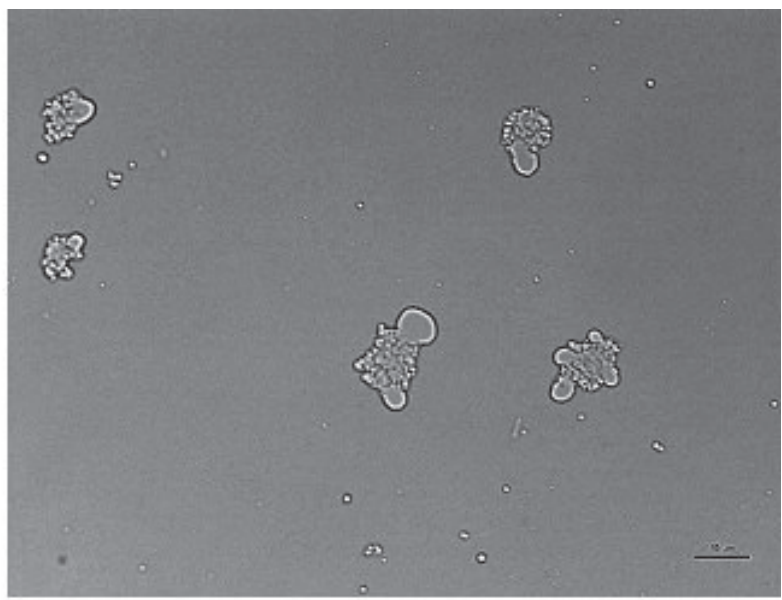

D

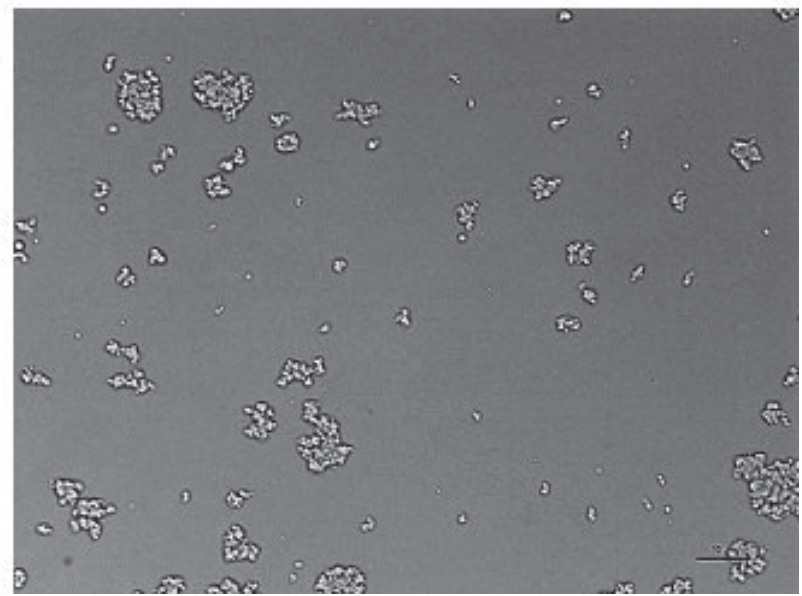

FIGURE 2. Microscopic images of unhomogenised cream (A) and cream homogenised under pressure of $100 \mathrm{MPa}$ at a temperature of $20^{\circ} \mathrm{C}(\mathrm{B}), 40^{\circ} \mathrm{C}(\mathrm{C})$, $60^{\circ} \mathrm{C}(\mathrm{D})$.

(Figure 1). This indicates a 4.7-6-fold reduction in the sizes of $d_{v} 10$ of fat globules as a result of full-stream homogenisation and a 2.3-2.7-fold reduction as a result of partial homogenisation (Table 2). Therefore, in the milk subjected to partial homogenisation, a reduction in fat globule sizes also occurs; however, some of the globules are found in the form of agglomerates (Figure 1E-1G). This is also confirmed by microscopic observation of homogenised cream used to standardize milk (Figure 2).

During the determination of the size of particles with a device using laser diffraction, the measurements were applied to fat globules as well as to the agglomerates, which, during the measurement, were counted as separate particles. The fact that during the study, both individual fat globules and their agglomerates were measured in the measurement cell, is fully justified as in the potential finished product, both agglomerates and fat globules are subject to the formation of the cream layer. Therefore, partial homogenisation of milk should also apply one of the methods used for preventing the fat globule agglomeration process, e.g. two-stage homogenisation or an addition of an emulsifier.

In the shaping of the degree of dispersion of milk fat, it is the composition of the product being homogenised (mainly the fat content-to-milk plasma protein content ratio) that is crucial. The main determinant of the effectiveness of ho- mogenisation is the fat content of the product and the number of surface-active plasma components, as they are involved in the reconstruction of an envelope on the newly-formed fat-milk plasma interfacial surface, i.e. on the surface of the fat globules being homogenised. The fat content-to-protein content ratio determines the size of fat globules as well as the associated surface of fat and the level of milk protein adsorption. In milk, the rate of protein adsorption on the surface of fat is higher than the rate of fat globule interactions, and, consequently, the dispersion of milk fat occurs (the so-called micronisation of the emulsion phase). With an increase in fat content, the rate of interactions between fat globules significantly exceeds the rate of protein adsorption on the fat/milk plasma interfacial surface and the effectiveness of the process decreases. This explains the increasing, stronger trend of fat globules for agglomeration at a high fat content and at high pressure, where the fat surface is too large for the envelopes to be completely reconstructed by the surface-active components of milk. It is considered that the main cause responsible for diminished effectiveness of homogenisation of dairy products with a high fat content, e.g. cream, is the flocculation, i.e. the formation of durable clusters of fat globules. This phenomenon is accompanied by a trend towards the formation of a cream layer on product surface. Such a state is referred to as viscolisation and the product is called viscolised. At elevated 

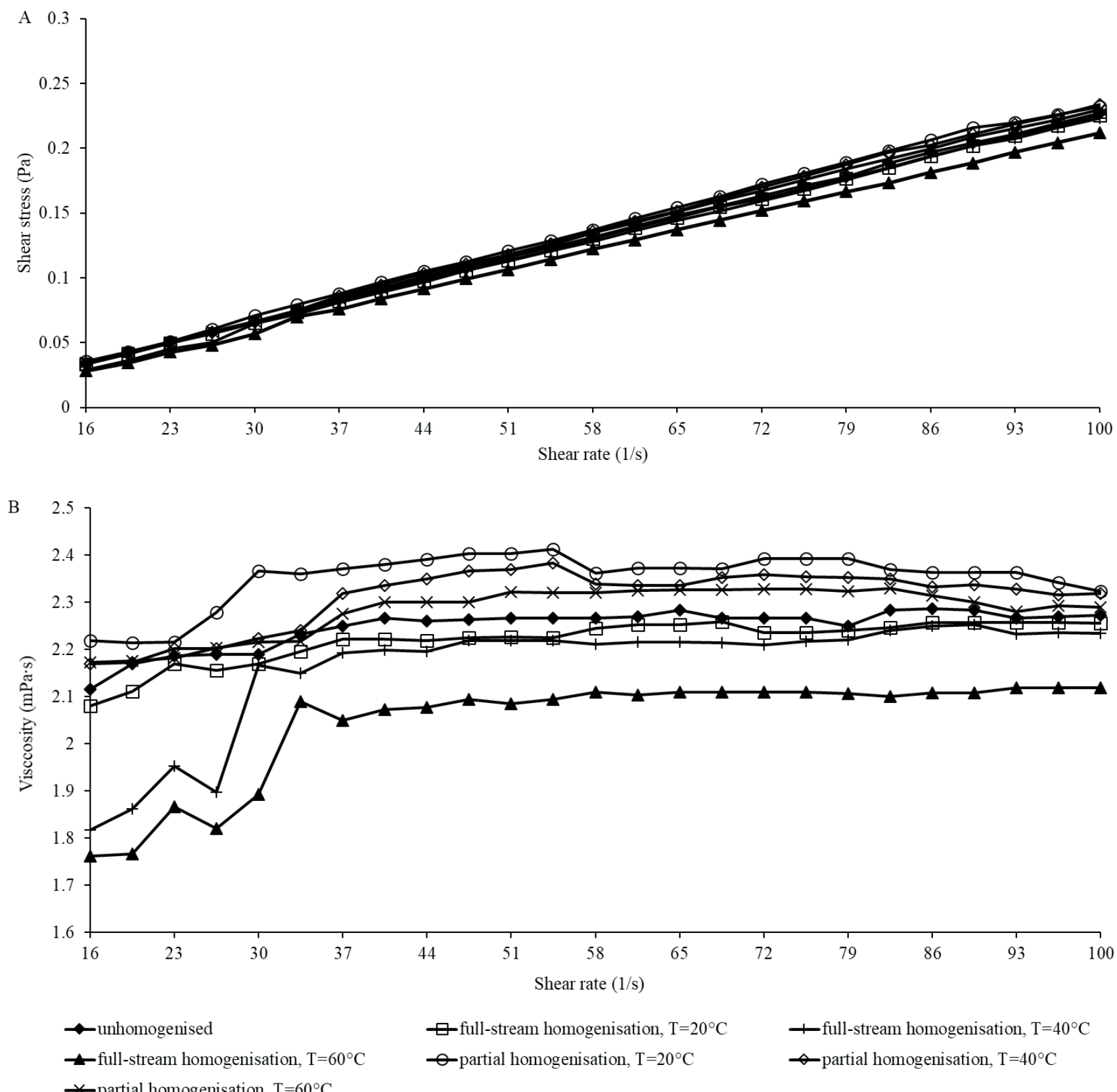

FIGURE 3. The effect of homogenisation on shear flow (A) and viscosity (B) of milk.

Legend: non-homogenised; $\boldsymbol{\Delta}$ full-stream homogenisation, $\mathrm{T}=60^{\circ} \mathrm{C} ;+$ full-stream homogenisation, $\mathrm{T}=40^{\circ} \mathrm{C}$; $\square$ full-stream homogenisation, $\mathrm{T}=20^{\circ} \mathrm{C} ; \times$ partial homogenisation, $\mathrm{T}=60^{\circ} \mathrm{C} ; \diamond$ partial homogenisation, $\mathrm{T}=40^{\circ} \mathrm{C} ; \circ$ partial homogenisation, $\mathrm{T}=20^{\circ} \mathrm{C}$

pressure and temperature parameters, the coalescence of fat globules may occur, which can contribute to the greater variation in fat globule sizes [Kessler, 1981; Rodarte et al., 2018].

During the research, milk shear flow curves were determined, and a similar course of changes was found, both as regards a control sample and all milk samples under analysis, subjected to high pressure homogenisation, regardless of the method or temperature applied (Figure 3A). An effect was found of full-stream high pressure homogenisation that viscosity decreased, when the temperature increased (Figure 3B). This was confirmed by the results of studies by Amador-Espejo et al. [2014] and by Pereda et al. [2007], who demonstrated a reduction in viscosity as a result of high pressure homogenisation carried out at pressures of up to $200 \mathrm{MPa}$, with a trend of changes developing with an increase in the temperature. The application of partial homogenisation contributed to an increase in milk viscosity, with an increasing range of changes, with a reduction in the temperature of milk earmarked for homogenisation. The effect of homogenisation on milk viscosity was statistically significant at $p<0.05$. The causes of the increase in milk viscosity occurring as a result of partial homogenisation, should undoubtedly be sought in the flocculation of fat globules as well as the presence of large agglomerates, confirmed by the results of measurement of particle sizes, and documented by microscopic images. The slight decrease in the viscosity of partially 
homogenised milk at higher shear rate values resulted probably from the breaking of fat globule agglomerates during the measurement.

\section{CONCLUSIONS}

Omission of the skimmed milk in the homogenisation process allows maintaining components of the colloidal and soluble phases at the least changed state. Milk properties that depend on milk plasma components (mainly proteins) are determined only through changes in the emulsion phase of cream, and are changed to the lowest extent in comparison to milk homogenised by a full-stream homogenisation. This mainly concerns rennet coagulation time and the heat stability of milk.

Striving to obtain the product with features most similar to those of raw milk, partial homogenisation seems to be the best technological solution. However, partial high pressure homogenisation is second to the process carried out by the full-stream homogenisation in terms of its effectiveness of dispersing fat globules in milk. Modification of the emulsion phase was reflected in the course of the viscosity curves subject to full-stream homogenisation (decrease) and partial homogenisation (increase). This drawback is caused by the fact that partial homogenisation results in the presence of post-homogenisation clusters in milk, which can, however, be split in the second stage of the process. This provides real opportunities for using partial homogenisation in combination with other alternative preservation methods which are non-invasive for milk components.

\section{RESEARCH FUNDING}

Project financially supported by Minister of Science and Higher Education in the range of the program entitled "Regional Initiative of Excellence" for the years 2019-2022, Project No. 010/RID/2018/19, amount of funding 12.000.000 PLN.

\section{CONFLICT OF INTEREST}

Authors declare no conflict of interest.

\section{REFERENCES}

1. Aguayo, E., Tarazona-Díaz, M.P., Martínez-Sánchez, A., García-González, A. (2017). Influence of moderate high-pressure homogenization on quality of bioactive compounds of functional food supplements. Journal of Food Quality, 2017, art. no. 2856125.

2. Amador-Espejo, G.G., Suàrez-Berencia, A., Juan B., Bárcenas, M.E., Trujillo, A.J. (2014). Effect of moderate inlet temperatures in ultra-high-pressure homogenization treatments on physicochemical and sensory characteristics of milk. Journal of Dairy Science, 97(2), 659-671.

3. AOAC (1990) Official Methods of Analysis. In K. Helrich (Ed.), Association of Official Methods of Analysis. 15th ed. Arlington, VA, pp. 804-830.
4. Banach, J.K., Żywica, R., Kiełczewska, K. (2008). Effect of homogenization on milk conductance properties. Polish Journal of Food and Nutrition Sciences, 58(1), 107-111.

5. Butz, P., Tauscher, B. (2002). Emerging technologies: chemical aspects. Food Research International, 35, 279-284.

6. Datta, N., Deeth, H.C. (2003). Heat treatment, alternatives to. In H. Roginski (Ed.-in-Chiefs), J. Fuquay, P. Fox (Eds.), Encyclopedia of Dairy Science, Academic Press Elsevier Sci. Ltd., pp. 1327-1346.

7. Devlieghere, F., Vermeiren, L., Debevere, J. (2004). New preservation technologies: possibilities and limitations. International Dairy Journal, 14, 273-285.

8. Dumay, E., Chevalier-Lucia, D., Picart-Palmade, L., Benzaria, A., Gracia-Julia, A., Blayo, C. (2013). Technological aspects and potential applications of (ultra) high-pressure homogenisation. Trends in Food Science and Technology, 31 (1), 13-26.

9. Georget, E., Miller, B., Aganovic, K., Callanan, M., Heinz, V., Mathys, A. (2014). Bacterial spore inactivation by ultra-high pressure homogenization. Innovative Food Science \& Emerging Technologies, 26, 116-123.

10. Hayes, M.G., Kelly, A.L. (2003a). High pressure homogenisation of raw whole bovine milk (a) effects on fat globule size and other properties. Journal of Dairy Research, 70(3), 297-305.

11. Hayes, M.G., Kelly, A.L. (2003b). High pressure homogenisation of milk (b) effects on indigenous enzymatic activity. Journal of Dairy Research, 70(3), 307-313.

12. Hernández, A., Harte, F.M. (2008). Manufacture of acid gels from skim milk using high-pressure homogenization. Journal of Dairy Science, 91(10), 3761-3767.

13. Innings, F. (2015) High pressure homogenizer design. In M. Rayner, P. Dejmek (Eds.), Engineering Aspects of Emulsification and Homogenization in the Food Industry, CRC Press Inc., Boca Raton, Florida, USA, pp. 149-168.

14. Kessler, H.G. (1981). Emulsifying - homogenizing. In A. Kessler (Ed.) Food Engineering and Dairy Technology, Freising, West Germany, pp. 119-138.

15. Kiełczewska, K., Kruk, A., Czerniewicz, M., Kopeć, M. (2008). Colloidal stability of milk with various content of fat subjected to high-pressure homogenization. Polish Journal of Food and Nutrition Sciences, 58(3), 359-363.

16. Kiełczewska, K., Kruk, A., Czerniewicz, M., Warmińska, M., Haponiuk, E. (2003). The effect of high-pressure homogenization on changes in milk colloidal and emulsifying systems. Polish Journal of Food and Nutrition Sciences, 12/53(1), 43-46.

17. Korhonen, H. (2009). Bioactive components in bovine milk. In Y. W Park (Ed.), Bioactive Components in Milk and Dairy Products, Wiley-Blackwell, A John Wiley \& Sons, Ltd., Publication, pp. $15-42$.

18. Kruk, A., Kisza, J., Palich, P. (1979). Comparison and evaluation of methods for determination of thermal stability of milk. Acta Academiae Agriculturae ac Technicae Olstenensis. Technologia Alimentorum, 15, 25-34 (in Polish, English abstract).

19. Kumar, P., Sharma, N., Ranjan, R., Kumar, S., Bhat, Z.F., Kee Jeong, D. (2013). Perspective of membrane technology in dairy industry: a review. Asian Australasian Journal of Animal Sciences, 26(9), 1347-1358.

20. Masson, L.M.P., Rosenthal, A., Calado, V.M.A., Deliza, R., Tashima, L. (2011). Effect of ultra-high pressure homogeniza- 
tion on viscosity and shear stress of fermented dairy beverage. LWT - Food Science and Technology, 44(2), 495-501.

21. Park, Y.W. (2009). Overview of bioactive components in milk and dairy products. In Y. W. Park (Ed.), Bioactive Components in Milk and Dairy Products, Wiley-Blackwell, A John Wiley \& Sons, Ltd., Publication, pp. 3-11.

22. Pedras, M.M., Pinho, C.R.G., Tribst, A.A.L., Franchi, M.A., Cristianini, M. (2012). Mini Review. The effect of high pressure homogenization on microorganisms in milk. International Food Research Journal, 19(1), 1-5.

23. Pedras, M.M., Tribst, A.A.L., Cristianini, M. (2014). Effects of high-pressure homogenisation on physicochemical characteristics of partially skimmed milk. International Journal of Food Science and Technology, 49(3), 861-866.

24. Pereda, J., Ferragut, V., Quevedo, J.M., Guamis, B., Trujillo, A.J. (2007). Effects of ultra-high pressure homogenization on microbial and physicochemical shelf life of milk. Journal of Dairy Science, 90(3), 1081-1093.

25. Pereda, J., Ferragut, V., Quevedo, J.M., Guamis, B., Trujillo, A.J. (2009). Heat damage evaluation in ultra-high pressure homogenized milk. Food Hydrocolloids, 23(7), 1974-1979.

26. Pereira, C., Henriques, M., Gomes, D., Gomez-Zavaglia, A., de Antoni, G. (2015). Novel functional whey-based drinks with great potential in the dairy industry. Food Technology and Biotechnolology, 53(3), 307-314..

27. Petrovska, S., Jonkus, D., Zagorska, J., Ciprovica, I. (2017). The influence of kappa-casein and beta-lactoglobulin genotypes on milk coagulation properties in Latvia dairy breed. Research For Rural Development, Annual 23rd International Scientific Conference Proceedings, 2, 74-80.

28. Polish Standard PN-A-86059. (1975). Milk, cream and sour cream. Determination of homogenisation efficiency (in Polish).

29. Roach, A., Harte, F. (2008). Disruption and sedimentation of casein micelles and casein micelle isolates under high-pressure homogenization. Innovative Food Science \& Emerging Technologies, 9(1), 1-8.

30. Rodarte, D., Zamora, A., Trujillo, A.-J., Juan, B. (2018). Effect of ultra-high pressure homogenization on cream: Shelf life and physicochemical characteristics. LWT - Food Science and Technology, 92, 108-115.
31. Sandra, S., Dalgleish, D.G. (2005). Effects of ultra-high-pressure homogenization and heating on structural properties of casein micelles in reconstituted skim milk powder. International Dairy Journal, 15(11), 1095-1104.

32. Sandra, S., Dalgleish, D.G. (2007). The effect of ultra-high-pressure homogenization (UHPH) on rennet coagulation properties of unheated and heated fresh skim milk. International Dairy Journal, 17(9), 1043-1052.

33. Sørensen, H., Mortensen, K., Sørlan, G.H., Larsen, F.H., Paulsson, M., Ipsen, R. (2014). Dynamic ultra-high pressure homogenisation of milk casein concentrates: Influence of casein content. Innovative Food Science \& Emerging Technologies, 26, 143-152.

34. Thiebaud, M., Dumay, E., Picart, L., Guiraud, J.P., Cheftel, J.C. (2003). High-pressure homogenisation of raw bovine milk. Effects on fat globule size distribution and microbial inactivation. International Dairy Journal, 13(6), 427-439.

35. Valsasina, L., Pizzol, M., Smetana, S., Georget, E., Mathys, A., Heinz, V. (2017). Life cycle assessment of emerging technologies: The case of milk ultra-high pressure homogenisation. Journal of Cleaner Production, 142(4), 2209-2217.

36. Yan, B., Park, S.H., Balasubramaniam, V.M. (2017). Influence of high pressure homogenization with and without lecithin on particle size and physicochemical properties of whey protein based emulsions. Journal of Food Process Engineering, 40(6), art. no. 12578.

37. Zamora, A., Ferragut, V., Guamis, B., Trujillo, A.J. (2012). Changes in surface protein of the fat globules during ultra-high pressure homogenisation and conventional treatments of milk. Food Hydrocolloids, 29(1), 135-143.

38. Zamora, A., Ferragut, V., Jaramillo, P.D., Guamis, B., Trujillo, A.J. (2007). Effects of ultra-high pressure homogenization on the cheese-making properties of milk. Journal of Dairy Science, 90(1), 13-23.

Submitted: 25 October 2018. Revised: 5 April and 30 May 2019. Accepted: 12 June 2019. Published on-line: 5 July 2019. 
